\title{
A Literatura para a Infância, a formação do Leitor Crítico e a Educação Intercultural ${ }^{\prime}$
}

\author{
Children's Literature for Critical Reading and Intercultural Education Training
}

\author{
MARIA HELENA RODRIGUES MAGALHÃES \\ Universidade do Minho \\ Portugal \\ magalhaesmariahelenarg64@gmail.com
}

(Recibido: I7-O2-202O; aceptado: $24-\mathrm{II}-2 \mathrm{O} 2 \mathrm{O}$ )

Resumo. Este estudo tem como objetivo central revelar o potencial educativo da literatura para a infância no desenvolvimento de uma consciência crítica sobre o mundo e na promoção do diálogo intercultural. Hoje, perante uma população multicultural crescente nas nossas escolas, urge refletir sobre esta temática e encontrar caminhos de aprendizagem cooperativa e solidária. Estão as escolas preparadas para este desafio? Quais as virtualidades da literatura infantil na promoção da educação intercultural? Estas questões nortearam todo o trabalho de investigação e criaram oportunidades de reflexão sobre estratégias de educação intercultural crítica, através do recurso à literatura infantil. Trata-se de um estudo com focagem qualitativa e abordagem crítica. Depois de efetuada uma pesquisa bibliográfica sobre o tema, procedemos a uma leitura aprofundada e análise crítica cruzada, dialogando com diferentes autores e correntes interpretativas. Tendo por base um referencial teórico devidamente sustentado, desenvolvemos um exercício de leitura crítica dos contos $O$ Patinho Feio, de Hans Christian Andersen, e Os Ovos Misteriosos, da autoria de Luísa Ducla Soares e Manuela Bacelar. Os contos selecionados põem em confronto paradigmas ideológicos e educativos divergentes e permitem desconstruir discursos e práticas monoculturais, combater atitudes discriminatórias e cooperar na edificação de atitudes positivas face à diferença.

Palavras-chave: multiculturalidade; diversidade; literatura infantil; literacia crítica; educação intercultural.

\footnotetext{
I Para citar este artículo: Rodrigues Magalhães, Ma Helena (2O2I). A Literatura para a Infância, a formação do Leitor Crítico e a Educação Intercultural. Alabe 23 [www.revistaalabe.com]

DOI: IO.I5645/Alabe2O2I.23.3
} 
Abstract. The objective of this study is to reveal the potential of Children's Literature in the development of critical thinking skills, as well as to promote an intercultural dialogue.Today, as multicultural populations grow in schools, it is vital to reflect on this topic and find platforms of understanding and cooperation. Are schools prepared for this challenge? What is the potential of Children's Literature to promote an intercultural education? The questions raised guide the research and create opportunities to reflect on critical intercultural educational strategies regarding to Children's Literature. This study follows a qualitative and critical approach. After performing bibliographic research on the topic, there was an in-depth reading and cross-critical analysis, in dialogue with different authors and interpretative currents. Based on a properly and supported framework, we have developed a critical reading of Ugly Duckling, by Hans Christian Andersen, and The Mysterious Eggs, by Luisa Ducla Soares and Manuela Bacelar.The selected tales confront divergent ideological and educational paradigms. They allow for the deconstruction of monocultural discourses and practices as they fight against discriminatory attitudes and cooperate in building positive attitudes.

Keywords: multiculturalism; diversity; children's literature; critical literacy; intercultural education. 
Tendo sido, durante séculos, um país de emigração, Portugal tem assistido, nas últimas décadas, a uma crescente diversidade étnica e cultural, fenómeno inerente ao processo acelerado de globalização nas sociedades tecnologicamente desenvolvidas em que já se integra e que se reflete na composição demográfica, socioeconómica e cultural das escolas. Fenómeno multifacetado com dimensões económicas, políticas, sociais, culturais, religiosas e jurídicas, complexamente imbricadas, a globalização atravessa fronteiras e dá-nos a conhecer o retrato do mundo como aldeia global. Este mundo, que na ótica de André (2006: 2-3), torna "vizinhos" os que longe habitam, proporciona-nos uma vivência contraditória da "familiaridade" e do "estranhamento" já que, se a aldeia facilita o (re) conhecimento, a multiplicação de ruas e estradas potencia o desconhecimento. E, se por um lado, a globalização parece homogeneizar, a verdade é que tal homogeneidade não permite "a perceção diferenciada da singularidade inalienável do outro" que torna o diálogo possível. Enclausurados numa nova "Torre de Babel” construída, não numa direção vertical, ligada ao transcendente, mas numa direção horizontal com o intuito de agilizar a comunicação entre os homens, navegamos numa labiríntica rede de encontros e desencontros, inábeis para atacar na raiz os problemas da intolerância, da violência, do racismo e da xenofobia, que se manifestam, frequentemente, em várias partes do globo.

Ecoando o pensamento do educador Paulo Freire, André (Idem: II) encara o ser humano como um "ser-no-mundo-com-os-outros", à escala planetária, mercê dos avanços tecnológicos, e reflete sobre os dois rostos da globalização: a "globalização de rapina" em que se traduz a globalização neoliberal e a "globalização da solidariedade", consentânea com os esforços empreendidos no sentido de "inventar novas formas ecoéticas de o homem se situar no mundo e dele fazer a sua casa." Esta última remete-nos para a necessidade de uma educação para a cidadania ativa, esclarecida e responsável, impulsionadora da autodeterminação comprometida com a emancipação social, uma educação que nos encoraje a (con)viver com os outros, assumindo direitos e deveres com a mesma convicção, e a sermos atores e coautores da vida social num contexto de diversidade cultural crescente.

Sobre o tema da diversidade cultural, importa refletir sem nos deixarmos enclausurar nas fronteiras de uma visão superficial e acrítica que, frequentemente, nos remete para dois antagónicos e frívolos discursos. Um associado à desvalorização do Diferente e, ordinariamente, ligado à marginalidade e exclusão social. O outro, politicamente correto, retórico e epidérmico, faz a apologia da diversidade cultural desprovida de qualquer conflito, uma diversidade cultural não problemática, "estilo Benetton" (Lluch \& Salinas, I996: 8I), que apela à paz mundial e à harmonia universal. Ao mesmo tempo que enfatizam as diferenças (desprezando-as ou enaltecendo-as), ambos asfixiam o debate ideológico que torna possível a reflexão sobre o contexto económico, social, político e educativo onde a diversidade cultural se aninha. Urge, pois, ensaiar uma abordagem sistémica das políticas educativas com as recentes mudanças sociais, repensar os sistemas educativos e rever formas inadequadas de gestão e organização escolar. Nesta conjuntura, a profissão docente é chamada a refletir sobre as suas competências e responsabilidades e ensaiar um 
modelo de escola capaz de responder aos desafios do local e do global, contribuindo para a formação de cidadãos do mundo, que valorizam as suas raízes culturais e constroem a sua autonomia em dialética com a liberdade do Outro.

Defendendo que a investigação e a reflexão crítica sobre a teoria e a prática pedagógicas só poderão ser profícuas, salientamos a nossa convicção de que é importante que os docentes intelectualizem as suas práticas, desnudando os quadros mentais que acompanham a sua ação, e ensaiem propostas educativas multirreferenciais, num permanente exercício de vigilância crítica e inconformada. Concordamos com Babo (2007: 287-288) quando refere que estamos em contacto permanente com estereótipos e preconceitos, sem possibilidade de escapatória. Chegam-nos através de todas as instâncias de socialização e, de um modo particularmente poderoso, através da publicidade, da imprensa escrita e até da literatura. Daí a importância de procedermos à sua desconstrução. Simplificadores "das relações entre o Eu e a complexidade da realidade em que o Outro se integra", os estereótipos constituem uma tendência universal para agrupar e categorizar acontecimentos, objetos e pessoas, com base em relações de semelhança e traduzem-se, frequentemente, em juízos de valor prematuros, quase sempre depreciativos, feitos com desconhecimento de causa. Ao seu lado, caminham os preconceitos e a discriminação, responsáveis por comportamentos lesivos das capacidades e dos direitos do Outro. Sendo inseparáveis da condição humana, os estereótipos infiltram-se, consciente e/ou inconscientemente, nos nossos pensamentos. Só o espírito crítico pode constituir uma barreia contra as suas manifestações e conduzir ao abandono de posturas pedagógicas estandardizadas e monoculturais.

Ao contrário do "professor monocultural" (Stoer, I994), que olha a diversidade cultural como perturbação e obstáculo ao processo ensino-aprendizagem, o "professor intercultural” assume o papel de mediador e promove a rentabilização de saberes e culturas. Procura compreender e dar a conhecer o mundo do Outro, partindo do seu enquadramento cultural, e empenha-se na construção de uma "escola para todos" que proporcione o tão desejado sucesso educativo, sem despersonalizar, nem aculturar. Esta postura pedagógica exige a passagem do professor culturalmente "daltónico” (Stoer \& Cortesão, I999), para o "professor intercultural", agente promotor de uma democracia aprofundada que desenvolve dispositivos pedagógicos na base da noção de cultura como prática social. Este profissional reflexivo e investigador analisa as caraterísticas da população escolar com quem trabalha, questiona a adequação de métodos e materiais pedagógicos, e ensaia propostas educativas que impulsionam o desenvolvimento autónimo e crítico dos alunos, divorciando-se das perspetivas que os consideram recetores passivos e acríticos dos saberes que lhes são fornecidos.

Nesta linha de pensamento, defendemos uma (trans)formação de professores aliada a um percurso de autorreflexão e aprendizagem permanente que auxilia o desmantelamento de visões acríticas e potencia a capacidade de atuar no respeito pelo diálogo entre culturas, em prol de uma sociedade mais justa e mais humana.

É nossa intenção trazer algum contributo para a reflexão sobre a temática da 
multi/inter/culturalidade, lançar um olhar renovado para as questões da literatura para a infância, à luz das grandes transformações da sociedade atual, e revelar o potencial educativo desta área de produção literária para desenvolver uma consciência crítica sobre o mundo e promover o diálogo intercultural.

A perspetiva de educação intercultural que defendemos insere-se no contexto amplo da educação para a cidadania global e congrega aspetos antirracistas e dinâmicas inclusivas de participação crítica na vida democrática. Reconhecemos na diversidade uma riqueza a ser explorada e assumimos o pluralismo como paradigma de todo o processo de ensino-aprendizagem. Valorizamos o seu papel propulsor de um diálogo positivo entre identidades e culturas em transformação mútua e assumimos a necessidade de educar para a literacia crítica, desde a mais tenra idade. Incidiremos, por isso, um olhar mais detalhado sobre o I. ${ }^{\circ}$ ciclo do ensino básico, uma etapa fundamental na aquisição de competências literácitas e na construção identitária.

Sendo possível e desejável trabalhar em muitas vertentes quando se aspira a um projeto de educação intercultural, elegemos a literatura de potencial receção leitora infantil como uma ponte a (re)construir e a atravessar, rumo ao conhecimento do Outro e ao autoconhecimento emancipatório.

Frequentemente catalogada como um subproduto da pedagogia e uma forma literária menor, mercê da pouca relevância que lhe dedicaram os estudos culturais e da apreciação da criança como um ser limitado ao nível das suas capacidades intelectivas e estético-valorativas, a literatura infantil, na opinião de alguns críticos, obriga a constrangimentos semióticos que retiram valor literário aos textos e põem a nu o seu caráter essencialmente moralista e pedagógico-didático. A este propósito, gostaríamos de sublinhar que a literatura de potencial receção leitora infantil é, antes de mais, literatura. Embora nem todas as obras escritas a pensar no destinatário criança possam ser integradas neste domínio, sê-lo-ão, tal como preconiza Mergulhão (2008: I5), aquelas que, atendendo à especificidade de um ser em formação e às naturais limitações do seu conhecimento enciclopédico do mundo, não se restrinjam a propor-lhe visões demasiado simplistas da realidade, utilizando uma linguagem desprovida de procedimentos retórico-expressivos, sob o pretexto de a instância descodificadora não conseguir aceder de forma autónoma a esse universo simbólico de representação do real. A adequação da literatura ao desenvolvimento cognitivo e interesses psicológicos da criança não implica sacrificar o texto literário na sua dimensão estética e a relação de proximidade que mantem com a pedagogia não lhe retira prestígio. Partilhamos com Cervera (I992: I4-I6) a opinião de que a literatura para a infância, pelo facto de ter que atender às necessidades da criança, está indubitavelmente ligada a conceitos psicopedagógicos. Os seus autores possuem legítimas preocupações educativas, embora se distanciem do didatismo e moralismo de outros tempos.

Clarificado o facto de nem todas as publicações para crianças poderem ser consideradas literatura, importa referir que a literatura infantil emerge mais como reflexo de experiências do que como um corpo organizado de conhecimentos, daí que a prioridade 
do formativo sobre o instrutivo seja determinante. Os seus objetivos fundamentais não se concentram na transmissão de conhecimentos, mas no despertar da emoção e da sensibilidade estética, no estímulo à imaginação criadora, à capacidade crítica, ao pensamento divergente. Concomitantemente, eleva-se o nível linguístico do leitor que se depara com surpresas linguísticas, imagens estimulantes, analogias e jogos de palavras que incitam a refletir sobre a língua e contribuem para a descoberta de vínculos entre os níveis morfológico, fonológico, semântico, sintático e pragmático. Produzida pelo jogo da criação, a linguagem literária distancia-se do carácter denotativo e isento de ambiguidade da linguagem utilitária, para se situar no extremo oposto, estabelecendo com o leitor uma comunicação profunda que exige a sua inclusão no processo criador.

Mergulhadas numa linguagem metafórica, as palavras surgem impregnadas de significados múltiplos, obrigando a estabelecer associações sugestivas e a descobrir aspetos ocultados pela rotina. Apresentam ao leitor novas formas de olhar a realidade, obrigando-o a ser criativo e a multiplicar sobre si mesmo os efeitos positivos dessa leitura caleidoscópica, aberta à possibilidade de mudança.

Confrontando a criança com uma linguagem simples, depurada e criativa, a leitura de textos literários para a infância possui um amplo espaço de liberdade para explorar, sem renunciar à sua vocação pedagógica e formativa, mas evitando moralismos extemporâneos e retórica vã. A exploração de temas universais como o amor, a amizade, a solidariedade, o respeito pelo Outro e pelo mundo em que vivemos, configuram tópicos de reflexão que, com a ajuda de mediadores de leitura conscientes da importância do seu papel, permitem desenvolver a competência leitora e o pensamento reflexivo da criança, na órbita de uma educação emancipadora que lhe permita aceder à compreensão do seu mundo interior e ao conhecimento da realidade circundante, impelindo-a a agir e a colaborar na sua transformação.

Esta visão educativa tem implícita uma postura pedagógica que coloca o leitor no âmago do processo de construção do(s) significado(s) do texto literário. O leitor, entidade indispensável à obra literária, não é um recetor passivo, mas um explorador inquieto, construtor e produtor de sentido. As crianças são naturalmente curiosas e questionadoras. Têm sede de aprender e desenvolvem precocemente comportamentos emergentes de leitor (Chall; Chauveau \& Rogovas-Chaveau cit. por Sousa, 2007: 46). Manifestam prazer em ouvir contar histórias, gostam de folhear os livros que os adultos lhes leem, falam sobre as suas histórias preferidas, nunca se cansam de as ouvir e manifestam, frequentemente, o desejo de aprender a ler.

Geralmente associado à entrada na escola do I. ${ }^{\circ}$ ciclo do ensino básico, o ensino da leitura é aguardado com expectativa por pais e encarregados de educação, mas sobretudo pelas crianças. Todavia, com bastante frequência, o entusiasmo inicial depressa se perde.

O aprendiz de leitor esperava poder entrar numa floresta em que por encanto penetraria num mundo de maravilhas e tesouros escondidos e é empurrado para um 
beco em que séries arrumadas de letras apenas lhe dão passagem para sílabas que, de forma espartilhada, se transformam em palavras isoladas, pouco atraentes e estimulantes [...] Algures, entre o mundo deslumbrante esperado e a realidade encontrada, instala-se a indiferença. [...] A forma mais ou menos eficaz e prazerosa como se processa a entrada formal no mundo das letras, i. é., a aprendizagem da decifração, é determinante no sucesso pessoal como leitor (Sim-Sim, 2009: 7).

A decifração, condição básica para que um leitor seja capaz de interagir com informação escrita, constitui uma técnica, um poderoso adestramento da capacidade de transformar uma imagem gráfica numa realização oral, que deve ser consolidado para que se possa aceder à compreensão e à construção de sentidos. Todavia, o ensino da leitura não deve ter como principal objetivo o treino de competências mecânicas. Esse treino, efetivamente necessário, tem que estar ao serviço de um projeto de leitura com sentido que reclama o ensino explícito da compreensão leitora através do desenvolvimento de capacidades metacognitivas, de processos de inferência e de estratégias de uso de conhecimentos extratextuais que convocam, no ato de leitura, a experiência pessoal do jovem leitor, envolvendo-o cognitiva e emocionalmente em todo o processo.

Não sendo uma atividade natural, o domínio da leitura requer um ensino direto, práticas intencionais e sistemáticas, esforço e determinação, facilitados por contextos ricos em experiências de leitura gratificantes, num processo que se vai aprofundando ao longo da vida, enquanto se vai aprimorando a capacidade de análise e o ambicionado pensamento crítico. A consciencialização de que os textos não representam o mundo de forma neutra exige uma pedagogia da literacia crítica capaz de formar leitores competentes que sabem fazer uso da sua capacidade de interrogar os textos para os des/re/ construir. Esta difícil pedagogia da literacia crítica, necessária ao exercício pleno da cidadania, encontra-se arredada da maioria dos contextos de ensino-aprendizagem da leitura, sobretudo nos anos iniciais de escolaridade.

A utilização frequente do manual de português como exclusivo recurso pedagógico, dificilmente contribui para fomentar o gosto pela leitura e formar leitores críticos que dialogam com os textos, indagando e construindo sentidos. Na verdade, a apresentação de textos fragmentados, excertos soltos e desgarrados, adaptações por vezes desastrosas, acompanhadas de questionários e propostas de análise e interpretação de sentido único, não contribuem para a promoção de uma educação literária, nem para o fomento de hábitos de leitura. Transformam os alunos em consumidores (e não intérpretes) de sentidos apontados por outros e não convergem para que usufruam de experiências de leitura estética e culturalmente relevantes (Balça, 2007: I3 ${ }^{\mathrm{I}-\mathrm{I} 3^{2}}$ ). Por todas estas razões, é imperioso que os docentes de língua portuguesa sejam leitores entusiastas capazes de transmitir a sua paixão pela leitura e, na posse do conhecimento de um vasto acervo literário, sejam capazes de proporcionar aos alunos experiências gratificantes de exploração de obras literárias que sugerem percursos múltiplos de leitura e geram importantes “efeitos perlocutivos" (Azevedo, 2006: I9). 
As crianças têm direito a uma aprendizagem da leitura que não ensine apenas a decifrar, mas que crie nelas o gosto pela leitura e fomente a capacidade de olhar a realidade de forma questionadora para nela intervir autónoma, crítica e solidariamente. A este propósito, cabe aqui referir o importante papel do Plano Nacional de Leitura (PNL) no reforço e alteração de práticas, tendo em vista a promoção da leitura e a valorização da literatura infanto-juvenil. Com efeito, a importância atribuída aos textos literários e a proposta de leitura integral de obras têm originado práticas inovadoras profícuas e estimulado um trabalho colaborativo entre alunos, professores, encarregados de educação e outros elementos da comunidade educativa. Tais práticas proporcionam às crianças a vivência de experiências gratificantes em torno dos livros e das histórias. Identificando-se com as personagens dos contos, descobrem na leitura de histórias inusitados sentidos e uma fonte inesgotável de prazer e desenvolvimento linguístico, cognitivo, afetivo e social. Além disso, as atividades orientadas em torno de projetos de leitura fundamentados na literatura têm potencialidades para laborar na direção da autonomia intelectual e moral das crianças e abrir perspetivas de posicionamento crítico diante da realidade.

De acordo com Bárbara Duque (2005) a viagem ao mundo das histórias é uma viagem ao interior de nós mesmos, onde por via do que nos é familiar e, através da capacidade de sonhar, apaziguamos os nossos medos, exprimimos desejos e emoções e encontramos respostas para os nossos conflitos interiores. Mas a viagem ao mundo das histórias é também uma viagem em direção ao Outro. Uma viagem de indagação, de questionamento, de estranheza, de deslumbramento e enriquecimento.

A temática da diversidade cultural tem, nos últimos anos, revelado um alargamento das áreas de reflexão, contemplando questões de diversidade étnica, questões de género, de orientação sexual, de credo religioso, de estatuto socioeconómico, de modelo de família, de diferentes aptidões/deficiências físicas e cognitivas, de temas específicos de determinadas culturas. Estas questões estão bem patentes na literatura infantil e lançam reptos à educação intercultural, motivando investigações diversas e propostas de modelos de análise de obras (Leite \& Rodrigues, 2OoO; Balça, 20o6; Morgado \& Pires, 2OIO).

Procurando construir um dispositivo de análise da literatura para a infância, Leite \& Rodrigues (2000: I5-I7) agrupam os livros em duas categorias muito gerais: os livros clássicos e os livros multiculturais. No primeiro grupo incluem os contos tradicionais e todos aqueles que, mesmo recentes, não manifestem o respeito pela diversidade cultural, enquanto no segundo grupo incluem os que manifestam essa preocupação e possuem intenções claramente pedagógicas. As autoras realçam, ainda, que os contos podem desempenhar um papel relevante na educação intercultural na medida em que abrem à criança a possibilidade de se identificar com personagens que interagem em contextos diversos, manifestando personalidades, comportamentos e valores distintos. Ao professor compete fomentar nos alunos a análise crítica das mensagens transmitidas pelos contos, (re) contextualizar as atitudes discriminatórias e valorizar as atitudes de solidariedade ativa. Neste sentido, mais do que promover a leitura de livros multiculturais, verdadeiramente importante é formar leitores críticos, aptos a examinar o mundo sob diversas perspetivas 
e contribuir para um processo de conhecimento e de transformação social. Formar leitores competentes, críticos e interventivos não constitui tarefa fácil e exige que os professores e outros mediadores de leitura de primeira linha sejam eles próprios leitores competentes, questionadores e críticos, num ato de criação permanente.

Procurando, em seguida, examinar de que forma a literatura infantil pode constituir um excelente recurso para a promoção da educação intercultural, traçaremos alguns caminhos de análise crítica de dois contos de autor: O Patinho Feio, obra clássica do dinamarquês Hans Christian Andersen aclamado por muitos críticos como o maior escritor de contos para crianças da literatura universal, e Os Ovos Misteriosos, da autoria de Luísa Ducla Soares, um nome incontornável no panorama da literatura portuguesa contemporânea para a infância. Estamos perante narrativas breves que apresentam uma ação linear, enredo simples e um reduzido número de personagens (Reis e Lopes, 2000; Coelho, 2009), que se movem num universo ficcional onde animais interagem com figuras humanas, articulando, de forma engenhosa, fantasia e realidade, numa dinâmica onde não falta a aventura. Com grande sensibilidade e qualidade retórico-estilística, retratam problemas relacionados com a natureza humana e abordam temáticas de crucial importância tais como: o preconceito, a rejeição, a discriminação, a descoberta da identidade, a aceitação da diferença, o respeito pelo Outro, a amizade, a partilha e a solidariedade. Encerram em si valores estéticos e éticos que abrem espaço para o questionamento e que, após um trabalho de exegese, permitem leituras cada vez mais profundas, contribuindo para a formação do leitor crítico e para a revisão de posturas etnocêntricas, muitas vezes ocultas e não intencionais.

Den grimme aellings, título original do conto escrito por Andersen, em I843, está traduzido em várias línguas, percorreu o mundo, atravessou várias gerações e, ainda hoje, prende a atenção das crianças. Escrita com estesia, a história desnuda o espírito diáfano e crítico do seu autor e conduz-nos a uma reflexão sobre a rejeição do Diferente, a busca da identidade, do autoconhecimento e da realização pessoal, por trajetórias onde a dor e a solidão se associam ao sonho e à ânsia de liberdade e emancipação. A personagem central da história é um patinho que nasce diferente dos seus irmãos. Na realidade, não era um pato, mas um cisne chocado no ninho de uma pata; um ninho cheio de ovos que, após um longo período de espera, eclodiram e de lá saíram umas belas criaturas que se maravilharam com o mundo. Mas um dos ovos parecia que não queria quebrar-se. Era um ovo diferente dos outros. De tal modo era grande que uma velha pata o confundiu com um ovo de peru.

- Deixa-me ver o ovo que não quer rebentar!- disse a velha. - Podes crer que é um ovo de peru! Também fui enganada uma vez e tive muitos aborrecimentos [...] É realmente um ovo de peru! Deixa-o ficar aí e ensina os outros filhotes a nadar! (Andersen, 2004:I6)

Apesar de cansada, a pata continuou a chocá-lo com infinita paciência até que, 
finalmente, o ovo grande rebentou.

Pi! Pi! Disse o filhote, deixando-se tombar para fora. Era tão grande e tão feio! A pata olhou para ele. - Mas é um patinho terrivelmente grande! Exclamou! [...] Espero que não venha a ser um peruzinho! (Idem: ı6).

As dúvidas foram desfeitas quando a mãe pata levou todos os patinhos para a água e vendo que o "filhote feio e cinzento também nadava" atestou que era seu filho e bastante bonito, quando se observava atentamente. Toda orgulhosa levou a sua prole para conhecer o mundo. Todos os patinhos foram considerados "bonitos", menos o que saíra em último lugar do ovo. Apelidado de feio e estranho, "foi mordido, tosado e dele escarneceram", por ser diferente (Idem: I7-I8).

Maltratado pelos patos, pelas galinhas, pela rapariga que distribuía comida aos animais e pelos próprios irmãos, o Patinho Feio só recebeu a aceitação da mãe que pedia a todos que não o importunassem. Não era bonito, mas não fazia mal a ninguém e até tinha bom feitio. Tinha passado demasiado tempo no ovo, justificava ela, mas com o tempo podia tornar-se bonito. Dizia isto enquanto lhe passava o bico na nuca, alisando-lhe as penas num gesto de ternura maternal. Contudo, com o passar do tempo, vendo que o seu filho era continuamente perseguido e maltratado por todos, a própria mãe suspirava "Quem me dera que fosses para longe!" Foi então que, triste e desiludido, sentindo-se rejeitado e abandonado, o Patinho, num ato de coragem, "elevou-se e voou para fora da sebe" (Idem: I9). Caminhou até ao pântano onde moravam os patos-bravos e também por eles foi apelidado de feio, embora isso não os incomodasse, desde que o patinho não quisesse casar e passar a pertencer à família deles. Ali permaneceu dois dias, até que se sentiu ameaçado por uns caçadores que dispararam contra os patos-bravos, tingindo de vermelho a água do pântano.

Muito amedrontado, o nosso herói conseguiu fugir e acabou por encontrar uma pobre casa de camponeses, onde morava uma velha senhora na companhia de um gato e de uma galinha, animais que protegia e estimava como se fossem seus filhos. Como a idosa senhora já não via bem, olhou para o Patinho e pôs a hipótese de se tratar de uma pata que lhe podia dar bons ovos e deixou-o ficar. O Patinho foi durante três semanas posto à prova e sujeitou-se às investidas dos donos da casa.

O gato, que era o senhor da casa e a galinha a senhora, diziam sempre: - Nós e o mundo! - pois acreditavam que eram metades deste e a melhor parte. Ao patinho parecia-lhe que se podia ter outra opinião, mas isso não suportava a galinha.

- Sabes pôr ovos? - perguntou ela.

- Não.

- Bem, então cala o bico!

E o gato dizia: - Sabes corcovar a espinha, bufar e fazer faíscas?

- Não. 
Então não deves ter opiniões quando fala gente razoável (Idem: 2I).

O Patinho mergulhava numa tristeza profunda e sentia uma ânsia de imergir a cabeça na água, nadar e flutuar, fantasias que os seus companheiros achavam um autêntico disparate. Incompreendido e infeliz, mas com vontade de seguir o seu sonho, aventurou-se no bosque onde enfrentou o frio impiedoso do inverno, viveu peripécias terríveis, conheceu a miséria e o infortúnio, até que chegou a primavera. Percebeu então que as suas asas tinham crescido, agitou-as fortemente e, sem perceber como, encontrou-se num belo jardim repleto de flores e frutos. É nesse ambiente primaveril que avista três belos cisnes brancos e decide voar na sua direção e nadar ao seu encontro, mesmo sabendo que corria o risco de ser picado de morte.

-Vá, matem-me! - disse o pobre animal, curvando a cabeça para a superfície da água à espera da morte (Idem: 24-25).

No momento em que vê o seu reflexo na água, compreende que é um cisne. Sente-se entre iguais que o acolhem e ouve um grupo de crianças exclamar que é o cisne mais jovem e belo do grupo. Compreende a sua origem e a sua identidade. Não é um Patinho Feio, rejeitado pela família que o viu nascer, mas um belo cisne.

Voltando agora a nossa atenção para Os Ovos Misteriosos, de Luísa Ducla Soares, com ilustrações de Manuela Bacelar, importa referir que se trata de uma obra destinada às primeiras idades, traduzida em francês e neerlandês, e recomendada pelo PNL. Bem acolhida pela crítica literária e amplamente divulgada, esta obra, editada pela primeira vez em I994, tem feito grande sucesso junto dos pequenos leitores. Trata-se de uma narrativa breve que se desenrola em torno de ações precisas através de um discurso vivo e sensorial, pontuado de pequenos diálogos e cativantes aspetos rítmicos e sonoros, como as rimas e as repetições, que conduzem à rápida memorização. A linguagem é habilmente utilizada numa vertente lúdica e melódica que atrai as crianças, moldando-se à sua capacidade de compreensão. A simplicidade lexical e sintática apresenta grande dinamismo e ganha contornos renovados quando se alia à leitura pictórica onde predominam as cores fortes, os tons quentes, os gestos e olhares expressivos das personagens que vivem situações invulgares, cómicas e absurdas. O padrão da normalidade é afrontado e impele a capacidade de sonhar. Os pequenos leitores sentem grande afinidade com as personagens da história, vivem através delas uma diversidade de situações emotivas e experimentam a alegria do triunfo da solidariedade contra as forças do mal.

A narrativa tem o seu início com a típica expressão "Era uma vez... "e conta-nos a história de uma galinha corajosa e determinada que acalentava o desejo de ser mãe.

- Já pus Iooo ovos. Podia ser mãe de mil filhos. Mas não tenho nenhum por causa da gente gulosa - cacarejou certa manhã a galinha (Soares, 2009: 2). 
Quando a dona entrou na capoeira, a galinha aproveitou a porta aberta e fugiu para a mata onde se dispôs a construir um confortável ninho. Depois de ter posto "um ovo muito branquinho" (Idem: 3 ) afastou-se para procurar comida, mas quando voltou ficou alegremente surpreendida ao ver o seu ninho repleto de "ovos de todos os tamanhos e feitios" (Idem: 4). Sem hesitação, decidiu começar a chocá-los.

Quando o primeiro ovo estalou e de lá saiu uma estranha criatura, a galinha exclamou com perplexidade: Ai, mas que filho,/ Eu até desmaio!/ Em vez de ser pinto/ é um papagaio (Idem: 6$)$.

O seu espanto prossegue com o nascimento posterior de uma serpente, uma avestruz, um crocodilo e um pinto. Muito orgulhosa, a galinha a todos mostrava a sua diversa ninhada e cuidou de todas as crias com igual amor e dedicação, ignorando os conselhos da perdiz: “ - Trata só do teu pinto. Não ligues aos outros bichos” (Idem: II).

A diversidade de gostos, de aptidões e comportamentos das crias exigiu da mãe galinha um esforço e dedicação constantes. Vivia num constante desassossego, mas a dedicação e o amor incondicional a todos os filhos possibilitaram uma convivência harmoniosa e conduziram a um sentimento de união entre todos.

Apesar das suas diferenças, as diversas personagens interagem entre si, sentem-se irmanadas e unem-se na adversidade contribuindo para a libertação do pinto que, entretanto, se tinha transformado num belo frango e que a mão inconsciente de um rapaz colocara numa situação de risco. Decidido a fazer um bom assado para o jantar, o rapaz apodera-se do frango e a partir desse ponto a história ganha um novo dinamismo. A autora faz desfilar perante nós as ações desenvolvidas por cada um dos irmãos para ajudar o que estava em perigo: a serpente assobiava "mostrando os dentes de veneno" (Idem: 26 ), o crocodilo avançava "de boca aberta" (Idem: 27), o papagaio gritava a plenos pulmões “És ladrão, és ladrão, vou prender-te na prisão!” (Idem: 28$)$ e a avestruz corria atrás do rapaz "a grande velocidade" (Idem: 29).

A ação concertada de todos os irmãos permitiu restituir a liberdade ao frango que voltou para casa para alegria de toda a família. Para comemorar, a galinha fez "um bolo com vários andares" (Idem: 30), com os alimentos favoritos de cada filho e todos cantaram em uníssono um elogio à diferença, à fraternidade e ao amor incondicional.

Procurando estabelecer alguns pontos de contacto entre as obras em análise, começamos por referir que a problemática da diversidade/ inclusão/ exclusão social constitui o eixo gerador das histórias e anuncia ao leitor crítico que a temática da diferença, muito em voga nos dias de hoje, desde épocas recuadas que tem sido alvo de reflexão, ainda que com focagem divergente.

A luta contra as adversidades faz parte da existência humana e ambas as histórias retratam este aspeto, mostrando aos pequenos leitores que é possível vencer dificuldades, se as encararmos com inteligência e determinação. Na verdade, a inteligência, a força de vontade, a coragem, a resiliência e os afetos emergem como ajudas preciosas para vencer as intempéries da vida, autênticas varinhas de condão, ao alcance de todos.

As personagens, maioritariamente animais antropomorfizados, para além das es- 
pecificidades próprias da sua condição animal, exibem caraterísticas temperamentais e condutas humanas. Marcadas pela diferença física e distintos modos de vida, seguem as suas inclinações naturais e procuram a felicidade e a realização pessoal, num mundo, por vezes, hostil e adverso. O pato e a galinha, personagens principais das histórias em análise, apesar de apresentarem caraterísticas físicas e psicológicas muito diferentes, possuem em comum uma atitude desafiadora perante os valores e consensos do seu tempo. Insatisfeitas e frustradas, assaltadas por dúvidas e inquietações, buscam a autorrealização, enfrentam perigos e obstáculos, longe da proteção oferecida pelo ambiente familiar, e ousam aventurar-se pelo desconhecido em busca de um lugar luminoso, onde os seus sonhos tivessem guarida. Os sonhos, oásis de liberdade, revelam um mundo de possibilidades, interpelam a ordem estabelecida e abrem caminho para a transformação da realidade. A galinha parte, impelida pelo desejo de ser mãe. O pato inicia a sua viagem em busca da aceitação social e afetiva que só encontrará entre iguais.

Ao analisarmos este último conto, começamos por verificar que a diversidade física, social, económica e cultural, está presente, mas as relações harmoniosas só acontecem dentro de cada grupo/classe social. A discriminação e exclusão social do Diferente são notórias e, ao longo da narrativa, avolumam-se atitudes racistas e situações de intolerância e violência física e psicológica.

Que aspecto tem aquele patinho! Não podemos tolerar isso! - E logo esvoaçaram [...] para o morder na nuca. [...] é demasiado grande e demasiado estranho [...] por isso tem de ser tosado! (Andersen, 2004: I8).

As relações de amizade são fundadas no respeito, lealdade e proteção e só são possíveis no seio de relacionamentos homogéneos. A educação, acentuadamente normativa e autoritária, configura um discurso pedagógico disciplinador que procura ajustar comportamentos, moldar consciências, desenvolver e fixar identidades.

Ao longo da narrativa, as representações sociais hegemónicas e as desigualdades sociais são evidenciadas. As vozes das culturas minoritárias são silenciadas e predominam estereótipos culturais e de género com papéis pré-estabelecidos. O estatuto e o papel da mulher são-nos revelados através da mãe dos patinhos, personagem afetuosa, dedicada à educação dos filhos. Humilde, submissa e resignada, assume uma postura de impotência face às situações de violência e frequentes humilhações de que o Patinho Feio é alvo, incapaz de encontrar solução para este tipo de problemas.

É também interessante verificar que existe uma mentalidade estereotipada relativamente ao sexo masculino. Detentor do poder em todas as áreas da vida social, é profundamente respeitado e nasce destinado a vencer, ainda que desprovido de beleza física.

- Ele não é bonito, mas tem bom feitio e nada bem como qualquer dos outros. [...] - Além disso é um pato [...] por isso não tem muita importância! Confio que venha a ter boas forças e vai vencer de certeza! (Idem: I8). 
Este conto apresenta ainda uma clara oposição entre o sonho e o lado materialista da vida. Como exemplo elucidativo evocamos o diálogo entre o Patinho Feio e os companheiros fiéis da velha camponesa que lhes deu abrigo. Estes, conformados com a sua situação, gratos por tudo o que recebiam da patroa, consideravam-se seres superiores e "diziam sempre: - Nós e o mundo! - pois acreditavam que eram metades deste e a melhor parte”. Não admitiam opiniões divergentes das suas e aconselhavam o Patinho a fazer algo de útil, como pôr ovos, bufar e fazer faíscas, para espantar as fantasias que lhe vinham à cabeça de "mergulhar" e "flutuar na água" (Idem: 2I). Não obstante, o nosso herói resolve seguir o seu instinto permitindo ao leitor concluir uma trajetória literária que culmina num final feliz: o encontro com os cisnes, a descoberta da sua identidade e a almejada aceitação social e afetiva.

Voltando agora o foco da nossa análise para o conto Os Ovos Misteriosos, verificámos que a valorização e o respeito pelas culturas na sua diversidade atravessam toda a narrativa e surgem enquadradas nos seus contextos, de forma não estereotipada. Identificam-se estilos de vida diversos e relações de amizade e cooperação entre as várias personagens. A amizade, firmada na confiança e no mútuo respeito, nasce de forma espontânea e é quotidianamente cuidada. É uma amizade familiar, mas é também uma amizade social e cultural; uma amizade com contornos universais, respeitadora das singularidades individuais e profundamente solidária; uma amizade que prende, porque cria laços de pertença, sem deixar de ser libertadora. Uma amizade assim só poderá germinar no seio de uma educação inclusiva que não encara a diferença como handicap, mas como agente catalisador de desenvolvimento e maturação individual e coletiva.

Toda a história se desenvolve em torno de uma conceção educativa assente em valores de abertura à mudança que acolhem o desejo de aventura e possibilitam o autoconhecimento, a autonomia de pensamento e de ação, a realização pessoal e a emancipação. Mas os caminhos percorridos não são solipsistas. São fundamentalmente caminhos de aprendizagem cooperativa que exaltam as virtualidades de uma convivência sã, no trilho de uma educação intercultural.

Este conto procura mostrar que, embora diferentes, somos todos iguais, já que temos os mesmos direitos, deveres e responsabilidades. Mas há muitos desafios a vencer para edificar este espírito de cidadania multi/inter/cultural. As palavras discriminatórias que acompanham atitudes racistas e xenófobas fazem-se ouvir (dentro e fora da história) na voz da perdiz que aconselhava a galinha “ - Trata só do teu pinto. Não ligues aos outros bichos" (Soares, 2009: II). Mas outras palavras inquietas se fazem ouvir pela boca do narrador: "como podia ela abandoná-los depois de os ter chocado com tanto amor?" (Idem: I2).

A temática da adoção e dos diferentes modelos familiares é aqui aflorada, bem como a questão da emancipação da mulher e o seu papel cada vez mais ativo na sociedade atual. Não nos deteremos nestes aspetos. O que nos parece importante frisar para finalizar este trabalho é que a questão da Diferença, que percorre os dois contos analisados, constitui um obstáculo à aceitação do Outro, que é sempre um mistério a desvendar. Para 
empreendermos essa tarefa (nunca acabada) é necessário afrontar o padrão da normalidade, questionar a nossa zona de conforto e delinear caminhos de reflexão crítica.

Do ponto de vista interpretativo, o texto tem uma grande margem de instabilidade. Há espaços em branco que é preciso preencher e discursos que é preciso desconstruir. No caso concreto das obras analisadas é importante desconstruir o discurso de repúdio pelo Diferente que, aos olhos do leitor mais desavisado, desaparece diante do final feliz da história. 


\section{Referèncias Bibliográficas}

- Andersen, H. C. (2004). O Patinho Feio. In Contos de H. C. Andersen (pp. I5-25). Porto: Público Comunicação Social.

- André, J. M. (2006). Identidade(s), multiculturalismo e globalização. A filosofia na era da globalização. Coimbra: Universidade de Coimbra.

-Azevedo, F. J. (2006). Literatura Infantil, Recepção Leitora e Competência Literária. In F. Azevedo (coord). Língua Materna e Literatura Infantil. Elementos nucleares para professores do Ensino Básico (pp. II-32). Lisboa: Lidel.

- Babo, M. A. (2007). Para uma desconstrução dos esteriótipos:"II2 gripes about the french" (1944-1945). In R. Bizarro (coord). Eu e o Outro. Estudos Multidisciplinares sobre Identidade(s), Diversidade(s) e Práticas Interculturais (pp. 287-30o). Porto: Areal.

- Balça, Â. (2006). A promoção de uma educação multicultural através da literatura infantil e juvenil. In F. Azevedo (coord). Língua Materna e Literatura Infantil. Elementos nucleares para professores do Ensino Básico (pp. 231-244). Lisboa: Lidel.

- Balça, Â. (2007). Da leitura à escrita na sala de aula: um percurso palmilhado com a literatura infantil. In F. Azevedo (coord). Formar Leitores. Das teorias às práticas (pp. I3I-I48). Lisboa: Lidel.

- Cervera, J. (I992). Teoria de la Literatura Infantil. Bilbao: Ediciones Mensajero.

- Coelho, N. N. (2009). Conto. In. C. Ceia (coord). E-Dicionário de Termos Literários. Documento online disponível em: https://edtl.fcsh.unl.pt/encyclopedia/conto/ (2I.II.2O).

- Duque, B. (2005). Um livro... Uma história...Interculturais. Lisboa: ACIME.

- Leite, C. y Rodrigues, M. L. (2000). Contar um conto, acrescentar um ponto. Uma abordagem intercultural na análise da literatura para a infância. Lisboa: IIE.

-Lluch, X., y Salinas, J. (i996). Uso (y abuso) de la interculturalidade. Cuadernos de Pedagogia, 252, 80-84.

- Mergulhão, T. L. F. M. (2008). Vozes e siléncio: a poética do (Des)encontro na literatura para jovens em Portugal. Tese de Doutoramento. Faculdade de Letras da Universidade de Lisboa.

- Morgado, M., y Pires, M. N. (20IO). Educação Intercultural e Literatura Infantil. Vivemos num mundo sem esconderïos. Lisboa: Colibri. 
- Reis, C. \& Lopes, A. C. M. (200o). Dicionário de Narratologia. Coimbra: Almedina.

- SIM-SIM, I. (2009). O ensino da Leitura: a decifração. Lisboa: ME. DGIDC.

- Soares, L. D. y Bacelar, M. (2009). Os ovos misteriosos. I3 3 edição. Porto: Afrontamento

- Sousa, O. C. (2007). O texto literário na escola: uma outra abordagem - Círculos de Leitura. In F. Azevedo (coord). Formar Leitores. Das teorias às práticas (pp. 45-68). Lisboa: Lidel.

- Stoer, S. (1994). Construindo a escola democrática através do "campo da contextualização pedagógica". Educação Sociedade e Culturas, I, 7-27.

- Stoer, S., y Cortesão, L. (1999). Levantando a pedra. Da pedagogia inter/multicultural às políticas educativas numa época de transnacionalização. Porto: Afrontamento. 